\title{
Excess molar volumes, intermolecular free lengths, adiabatic compressibilities and acoustic impedance of binary mixtures of anisole, toluene and ethylbenzene with dioxane at different temperatures
}

\author{
S. L. Dahire ${ }^{1, *}$, Y. C. Morey ${ }^{2}$, P. S. Agrawal ${ }^{3}$ \\ ${ }^{1}$ Department of Chemistry, Sindhu Mahavidyalaya, Nagpur, India \\ ${ }^{2}$ Department of Chemistry, Hislop College, Nagpur, India \\ ${ }^{3}$ Laxminarayan Institute of Technology, Nagpur, India \\ *E-mail address: dahire.sunil08@gmail.com
}

\begin{abstract}
The present study reports densities $(\rho)$, viscosities $(\eta)$ and ultrasonic speeds $(U)$ of pure dioxane (DOX), anisole (ANS), toluene (TOL) and ethylbenzene (ETB) and their binary liquid mixtures over the entire composition range at 293,298, 303, 308 and $313 \mathrm{~K}$. From the experimental data excess molar volume $\left(\mathrm{V}_{\mathrm{m}}^{\mathrm{E}}\right)$, excess intermolecular free length $\left(\mathrm{L}_{\mathrm{f}}^{\mathrm{E}}\right)$, excess adiabatic compressibility $\left(\beta^{\mathrm{E}}\right)$ and excess acoustic impedance $\left(\mathrm{Z}^{\mathrm{E}}\right)$ have been computed. The excess values were correlated using Redlitch-Kister polynomial equation to obtain their coefficients and standard deviations $(\sigma)$. With increase in temperature, the binary mixture of DOX+ANS shows larger deviations in $\beta^{\mathrm{E}}, \mathrm{L}_{\mathrm{f}}^{\mathrm{E}}$ and smaller deviations in $Z^{\mathrm{E}}, \mathrm{V}_{\mathrm{m}}^{\mathrm{E}}$. These results suggest that ANS has strong molecular interactions with DOX than ETB and TOL.
\end{abstract}

Keywords: Acoustical Properties; Excess Parameters; Redlich-Kister polynomial equation; Dioxane and Binary liquid mixtures

\section{INTRODUCTION}

Ultrasound waves are high frequency mechanical waves which affect the physical properties of the medium and hence can furnish information about molecular interactions of the liquid and liquid mixtures. Studies of thermodynamic properties of binary mixtures are of considerable interest in the fundamental understanding of the nature of interactions between the unlike molecules. In recent years, the theoretical and experimental investigations of excess and deviation functions are taken as interaction parameters to improve the results ${ }^{1-3}$.

DOX is an inert solvent having dielectric constant 2.2 at $298 \mathrm{~K}$. ANS is a polar but TOL and ETB are non-polar molecules and are important components in industries. In view of their industrial importance, the present study reports the experimental values of densities $(\rho)$, viscosities $(\eta)$ and ultrasonic speeds $(\mathrm{u})$ of binary mixtures of ANS, TOL, ETB with DOX over the entire composition range at 293, 298, 303, 308 and $313 \mathrm{~K}$.

The experimental data have been used to evaluate the excess molar volume $\left(\mathrm{V}_{\mathrm{m}}{ }^{\mathrm{E}}\right)$, excess intermolecular free length $\left(\mathrm{L}_{\mathrm{f}}^{\mathrm{E}}\right)$, excess adiabatic compressibility $\left(\beta^{\mathrm{E}}\right)$ and excess 
acoustic impedance $\left(\mathrm{Z}^{\mathrm{E}}\right)$ at each temperature. The excess values were correlated using the Redlich-Kister polynomial equation to obtain their coefficients and standard deviations.

\section{EXPERIMENTAL}

The liquids for present investigation DOX, ANS, TOL and ETB (S.D. Fine Chem. Ltd. India, A.R grade 99.5\%) were used without further purification. The liquid mixtures of different compositions were prepared by mixing calculated volumes of each component. In all systems, the various concentrations of the binary liquid mixtures were prepared in terms of mole fraction.

The mole fractions of the first and second component $\left(\mathrm{X}_{1}\right.$ and $\left.\mathrm{X}_{2}\right)$ were varied from 0 to 1. The density, viscosity and velocity were measured as a function of composition of binary liquid mixture at different temperatures 293-313 K. The density of sample was measured using digital densitometer (Rudolph) with an accuracy of $0.0001 \mathrm{gm} \mathrm{cm}^{-3}$. An Ostwald's viscometer was used for the viscosity measurements. Ultrasonic velocity measurement was made by variable path single crystal Interferometer (Mittal Enterprises, Model F-81) at 2 $\mathrm{MHz}$ with accuracy of $\pm 0.03 \%$.

An electronically digitally operated (Plasto Craft Industries) low temperature bath model, LTB-10 was used to circulate water. The accuracy in the temperature measurement is $\pm 0.1 \mathrm{~K}$. Reliability of the experimental data and the purity of the solvents were ascertained by calculating their densities, ultrasonic speeds and viscosities at different temperatures with the values reported in literature ${ }^{4}$.

\section{THEORY}

The excess parameters which play a major role in understanding the nature of molecular interaction in liquid mixtures have been studied by several workers, ${ }^{\mathbf{5 , 6}}$. The excess thermodynamic parameters are defined as the difference between the experimental and ideal mixture values. It gives a measure of the non- ideality of the system as a consequence of associative or of other interactions. The values of excess molar volumes $\left(\mathrm{V}_{\mathrm{m}}^{\mathrm{E}}\right)$, excess intermolecular free length $\left(\mathrm{L}_{\mathrm{f}}^{\mathrm{E}}\right)$, excess acoustic impendence, $\left(\mathrm{Z}^{\mathrm{E}}\right)$ and excess adiabatic compressibility $\left(\beta^{\mathrm{E}}\right)$ were calculated with the help of the following standard relations:

$$
\mathrm{Y}^{\mathrm{E}}=\mathrm{Y}_{\text {exp. }}-\left(\mathrm{X}_{1} \mathrm{Y}_{1}+\mathrm{X}_{2} \mathrm{Y}_{2}\right)
$$

where,

$Y_{\text {exp. }}=$ experimental values of mixtures

$\mathrm{Y}_{1} \& \mathrm{Y}_{2}=$ values of parameters for liquids 1 and 2 respectively.

$\mathrm{X}_{1} \& \mathrm{X}_{2}=$ mole fractions of liquid 1 (OX or MX or PX) and liquid 2 (STY).

The values of excess adiabatic compressibility $\left(\beta^{\mathrm{E}}\right)$, free length $\left(\mathrm{L}_{\mathrm{f}}^{\mathrm{E}}\right)$, acoustic impedance $\left(\mathrm{Z}^{\mathrm{E}}\right)$ and molar volume $\left(\mathrm{V}_{\mathrm{m}}^{\mathrm{E}}\right)$ for each mixture have been least-squares fitted to Redlich-Kister type polynomial equation given in literature ${ }^{7}$ by taking the limits $\mathrm{n}=0$ to $\mathrm{i}$.

$$
\mathrm{F}(\mathrm{X})=\mathrm{X}_{1}\left(1-\mathrm{X}_{1}\right) \Sigma \mathrm{A}_{\mathrm{i}} \cdot(1-2 \cdot \mathrm{X} 1)^{\mathrm{i}}
$$

where

$\mathrm{F}(\mathrm{X})$ refers to $\mathrm{V}_{\mathrm{m}}^{\mathrm{E}}, \beta^{\mathrm{E}}, \mathrm{Z}^{\mathrm{E}}$ or $\mathrm{L}_{\mathrm{f}}^{\mathrm{E}}$. 
The coefficient Ai is the polynomial coefficient tabulated by using the least square method computed by the MAPLE software has been used. The values of the standard deviation $^{8}(\sigma)$ were obtained from the expression

$$
\sigma=\left\{\sum(\mathrm{F}(\mathrm{x}) \exp -\mathrm{F}(\mathrm{x}) \mathrm{cal})^{2} /(\mathrm{k} / \mathrm{n})\right\}^{1 / 2}
$$

where

$\mathrm{k}$ is the number of experimental points excluding the end points and $\mathrm{n}$ is order of polynomial equation.

\section{RESULTS AND DISCUSSION}

The excess values of intermolecular free length $\left(\mathrm{L}_{\mathrm{f}}^{\mathrm{E}}\right)$, adiabatic compressibility $\left(\beta^{\mathrm{E}}\right)$, acoustic impedance $\left(\mathrm{Z}^{\mathrm{E}}\right)$ and molar volume $\left(\mathrm{V}_{\mathrm{m}}^{\mathrm{E}}\right)$ plotted against mole fraction of binary mixtures of DOX at 293-313K are shown in Fig. 1-12.

For ideal solutions the excess values are expected to be zero. The deviations indicate the nonideality of the solutions and are attributed mainly to different types of interactions. It can be seen that excess values may be affected by several factors.

i) The first factor is the specific forces between molecules such as hydrogen bonds, charge transfer complexes, breaking of hydrogen bonds and complexes bringing negative excess values.

ii) The second factor is the physical intermolecular forces including electrostatic forces between charged particles and a permanent dipole, induction forces between a permanent dipole and an induced dipole, forces of attraction and repulsion between non-polar molecules. Physical intermolecular forces are weak and the sign of excess value may be positive or negative.

iii) Third factor is the structural characteristics of the component arising from geometrical fitting of one component into other structure due to the differences in shape and size of the components ${ }^{9-13}$.

Positive deviations of $\mathrm{Lf}^{\mathrm{E}}, \mathrm{Vm}^{\mathrm{E}}, \mathrm{Z}^{\mathrm{E}}$, and $\beta^{\mathrm{E}}$ in binary systems have been attributed to dispersion forces and negative deviation is due to dipole-dipole and induced dipole interactions. Dispersion forces are operative in all systems, but since more than one type of interactions are present between the components, the excess values are the net result of all type of contributions ${ }^{14}$.

Fig. 1, 5 and 9 are the plots of $\beta^{\mathrm{E}}$ against mole fraction of DOX with ANS, TOL and ETB respectively. These plots show variation of $\beta^{\mathrm{E}}$ values with mole fraction of DOX as well as the effect of temperature. $\beta^{\mathrm{E}}$ exhibits negative behavior in all the systems throughout the concentration and temperature range studied, except for DOX + TOL and DOX + ETB where they possess variation of positive and negative values. $\beta^{\mathrm{E}}$ values of DOX + ANS are negative.

The behaviors of DOX + TOL and DOX + ETB possess negative values at lower temperature and finally reach to positive values. The observed values indicate that dipoledipole interactions decrease with increase of temperature.

This fact indicates that the strength of complexation of DOX is greater in ANS than TOL and ETB. It has been observed that intermolecular interaction decreases with increase of temperature. The above fact confirms that weak dipole-induced dipole interactions dominate 
over complex formation between unlike molecules. The change from positive to negative $\beta^{\mathrm{E}}$ values indicating the dissociation between the components and may be quantitatively interpreted in terms of detachment of unlike molecules leading to increase in compressibility and volume ${ }^{15}$.

In the liquid mixtures, the intermolecular interaction might result in the decrease of the interspaces between molecules and this might lead to a decrease in intermolecular free length producing negative values for the excess intermolecular free length $\left(\mathrm{L}_{\mathrm{f}}^{\mathrm{E}}\right)$. S. Azhagiri ${ }^{16}$ indicates that the positive values of excess free length should be attributed to the dispersive forces and negative excess values should be due to charge transfer for all the systems.

Fig. 2, $\mathbf{6}$ and 10 are the plots of $\mathrm{L}_{\mathrm{f}}^{\mathrm{E}}$ against mole fraction of DOX with ANS, TOL and ETB respectively. These plots show variation of $\mathrm{L}_{\mathrm{f}}^{\mathrm{E}}$ values with mole fraction of DOX and the effect of temperature. The values of $\mathrm{L}_{\mathrm{f}}^{\mathrm{E}}$ are negative for DOX + ANS and are positive for DOX + TOL and DOX + ETB. The observed fact indicates that DOX strongly interact with ANS than TOL and EBT. The strong interaction might have resulted in the decrease of interspaces between molecules. This might lead to decrease in intermolecular free length producing negative values for excess intermolecular free length ${ }^{17}$.

Fig. 3, 7 and 11 are the plots of $Z^{\mathrm{E}}$ verses mole fraction of DOX with ANS, TOL and ETB respectively. These plots show variation of $Z^{\mathrm{E}}$ values with mole fraction of DOX at various temperatures. For the systems of DOX, the interactions between unlike molecules are quite obvious. In case of DOX + ANS system $L_{f}^{E}, V_{m}^{E}$ and $\beta^{E}$ are negative and the values of $Z^{\mathrm{E}}$ positive. In case of DOX + TOL and DOX + EBT systems $\mathrm{L}_{\mathrm{f}}^{\mathrm{E}}, \mathrm{V}_{\mathrm{m}}{ }^{\mathrm{E}}$ and $\beta^{\mathrm{E}}$ are positive and the values of $Z^{\mathrm{E}}$ negative. The observed negative deviation in $Z^{\mathrm{E}}$ and opposite behavior of $\mathrm{L}_{\mathrm{f}}^{\mathrm{E}}$, $\mathrm{V}_{\mathrm{m}}^{\mathrm{E}}$ and $\beta^{\mathrm{E}}$ over the entire range of mole fraction of the system investigated again supports our view that the molecular interactions between the unlike molecules are quite obvious.

Molar excess volumes $\left(\mathrm{V}_{\mathrm{m}}^{\mathrm{E}}\right)$ are found to be very sensitive towards mutual interactions between component molecules of the liquid mixtures. The sign and extent of deviation of these functions from ideality depend on the strength of interactions between unlike molecules ${ }^{18}$.

A qualitative explanation is given for the change in $\mathrm{V}_{\mathrm{m}}{ }^{\mathrm{E}}$ with composition and temperature. Thus, it is interesting to note that the results obtained so far suggest that the values of $\mathrm{V}_{\mathrm{m}}^{\mathrm{E}}$, for the present systems, are essentially influenced by different factors as given in the literature ${ }^{19}$.

i) Structure making dipole-dipole or dipole-induced dipole $(\pi \ldots \pi)$ type specific interactions.

ii) Geometrical fitting of smaller molecules into the voids created by larger molecules due to the difference in molar volumes.

iii) Disruption of dipolar association present in the liquid components tends to make $V_{m}{ }_{m}^{E}$ positive.

The observed negative $\mathrm{V}_{\mathrm{m}}^{\mathrm{E}}$ values suggest that the combined effect due to (i) and (ii) dominates over that of (iii).

The sign of $\mathrm{V}_{\mathrm{m}}^{\mathrm{E}}$ of a system depends upon the relative magnitude of expansion and contraction of the two liquids due to mixing ${ }^{\mathbf{2 0}}$. If the factors causing expansion dominate the contraction factors, the $\mathrm{V}_{\mathrm{m}}^{\mathrm{E}}$ becomes positive. On the other hand if the contraction factors dominate the expansion factors, then $\mathrm{V}_{\mathrm{m}}^{\mathrm{E}}$ become negative. The factors that are responsible for expansion in volume are as follows, 
i) Loss of dipolar association,

ii) The geometry of molecular structure, which does not allow fitting of one component into other component,

iii) Steric hindrance, which opposes the proximity of the constituent molecules.

The negative $\mathrm{V}_{\mathrm{m}}{ }^{\mathrm{E}}$ values arise due to dominance of the following factors.

i) Chemical interaction between constituent chemicals.

ii) Accommodation of molecules of one component into the interstitials of the molecules of the other component.

iii) Geometry of the molecular structure that favors fitting of the component molecules with each other. The negative $\mathrm{Vm}^{\mathrm{E}}$ values in the mixtures under study indicate that interactions between molecules of the mixtures are stronger than interactions between molecules in the pure liquids and that associative force dominate the behavior of the solution $^{21}$.

Fig. 4, 8 and 12 show the variation excess molar volume, $V_{m}{ }^{E}$ for binary mixtures of DOX with ANS, TOL and ETB respectively. The values vary with mole fraction of DOX and temperature. The values are negative for DOX + ANS while the values are positive for DOX + TOL and DOX + ETB. The observed negative values of $\mathrm{V}_{\mathrm{m}}^{\mathrm{E}}$ for the binary mixture indicates the presence of specific interactions between DOX and ANS molecules. The negative $\mathrm{V}_{\mathrm{m}}{ }^{\mathrm{E}}$ values are attributed to strong dipole-dipole interactions between unlike molecules in the mixtures.

The negative values may arise due to interactions between the pi electrons of ANS with DOX. The structure making dipole-induced dipole interaction takes place resulting in negative $\mathrm{V}_{\mathrm{m}}{ }^{\mathrm{E}}$ value. The positive values either may be due to interruption of dipolar association in the binary mixtures of DOX with TOL and ETB or attributed to weak dipoledipole interactions between unlike molecules in the mixtures ${ }^{22-24}$. It has been observed that the values of $\mathrm{Vm}^{\mathrm{E}}$ shows negative deviation for the mixture of DOX with ANS and positive deviations for the mixtures of DOX with ETB \& TOL and follows the sequence: Anisole> Ethylenebenzene $>$ Toluene.

The Tables 1, 2, 3, 4 and 5 includes values of coefficient Ai which is the polynomial coefficient of Redlitch- Kister polynomial equation for binary mixtures of DOX with ANS, TOL and ETB at 293, 298, 303, 308 and 313K temperatures respectively. The tables show variations of smoothened values of excess parameters $\beta^{\mathrm{E}}, \mathrm{L}_{\mathrm{f}}^{\mathrm{E}}, \mathrm{Z}^{\mathrm{E}}$ and $\mathrm{V}_{\mathrm{m}}{ }^{\mathrm{E}}$ with temperature. It is clear from these tables that the values of all these excess parameters show small deviations for the mixtures of ANS, ETB and TOL with DOX.

With increase in temperature, the binary mixture of DOX +ANS shows the large value of standard deviations $(\sigma)$ of excess parameters $\beta^{\mathrm{E}}, \mathrm{L}_{\mathrm{f}}^{\mathrm{E}}$ and small values of standard deviations of excess parameters $\mathrm{Z}^{\mathrm{E}}, \mathrm{V}_{\mathrm{m}}^{\mathrm{E}}$. These results suggest that ANS has strong molecular interactions with DOX than the binary mixtures of DOX with ETB and TOL and follows the sequence: Anisole $>$ Ethylenebenzene $>$ Toluene. 


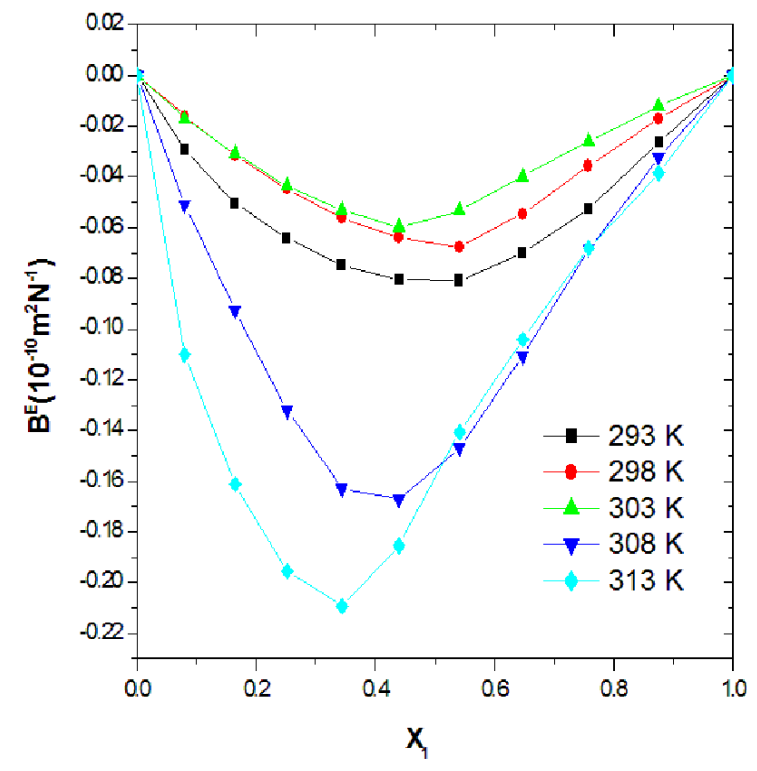

Fig. 1. Plots of $\beta^{\mathrm{E}}$ Vs. $\mathrm{X}_{1}$ for DOX+ANS

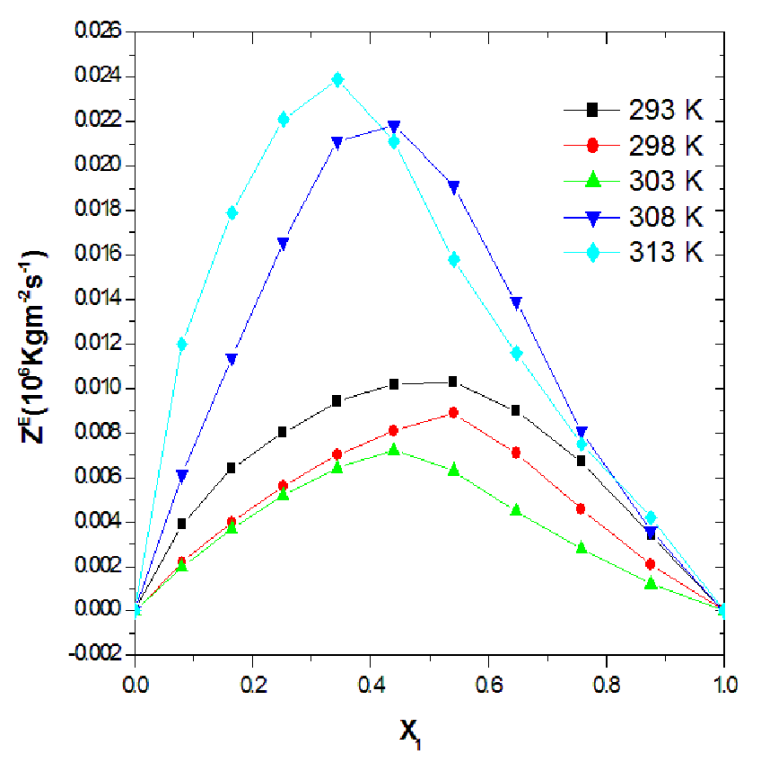

Fig. 3. Plots of $Z^{\mathrm{E}}$ Vs. $\mathrm{X}_{1}$ for $\mathrm{DOX}+\mathrm{ANS}$

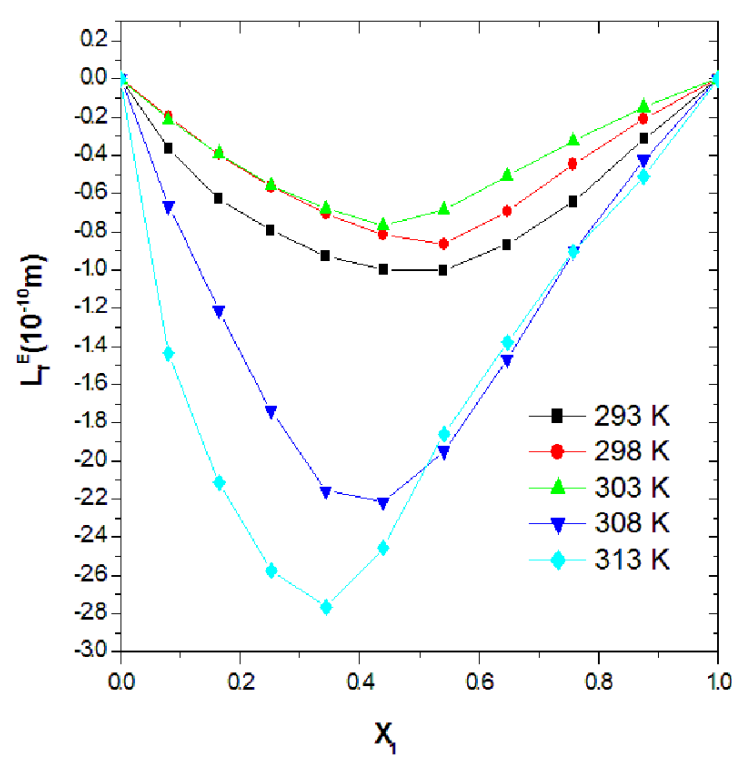

Fig. 2. Plots of $\mathrm{L}_{\mathrm{f}}^{\mathrm{E}}$ Vs. $\mathrm{X}_{1}$ for $\mathrm{DOX}+\mathrm{ANS}$

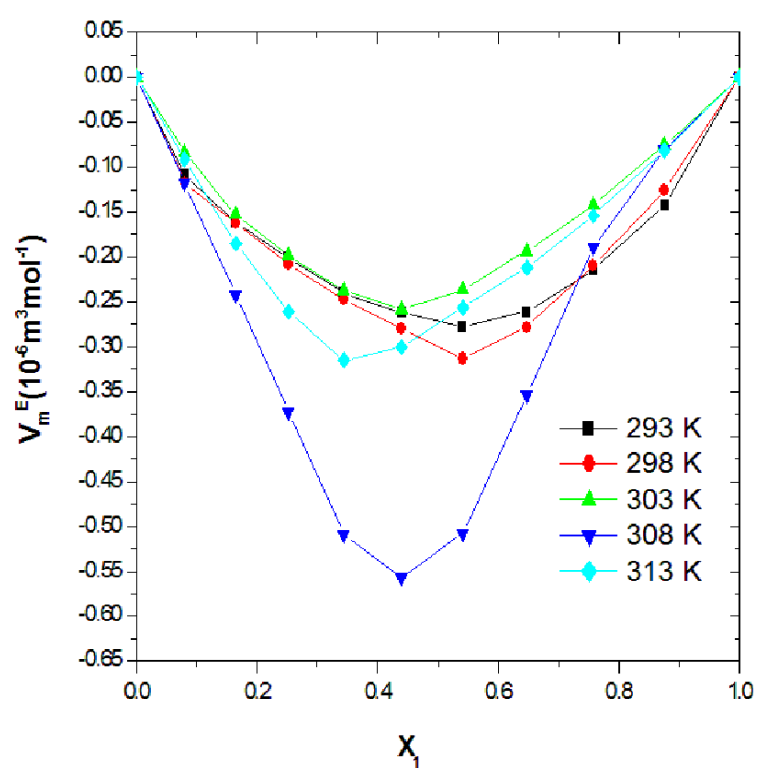

Fig. 4. Plots of $\mathrm{V}_{\mathrm{m}}^{\mathrm{E}} \mathrm{Vs}$. $\mathrm{X}_{1}$ for DOX+ANS 


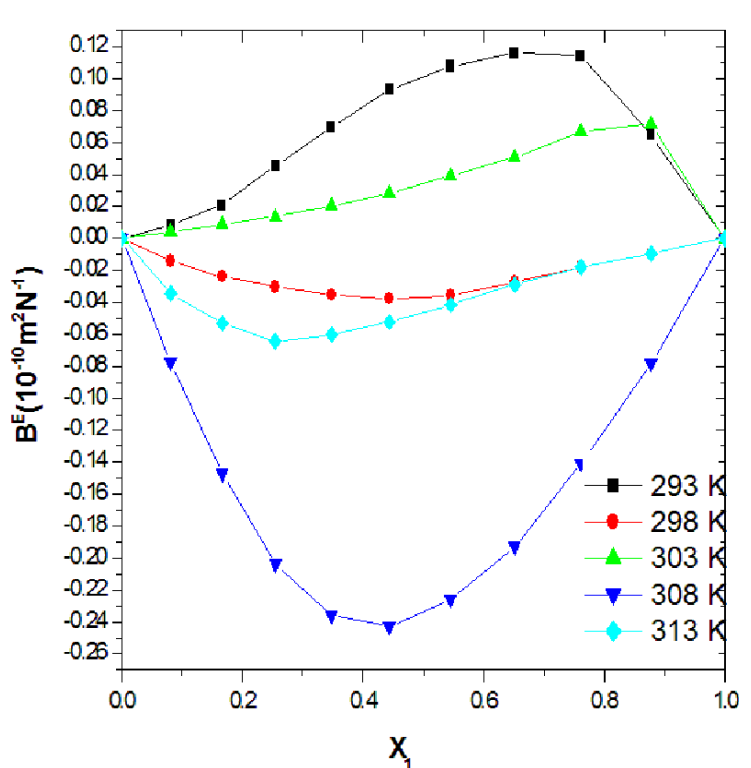

Fig. 5. Plots of $\beta^{\mathrm{E}}$ Vs. $\mathrm{X}_{1}$ for DOX+TOL

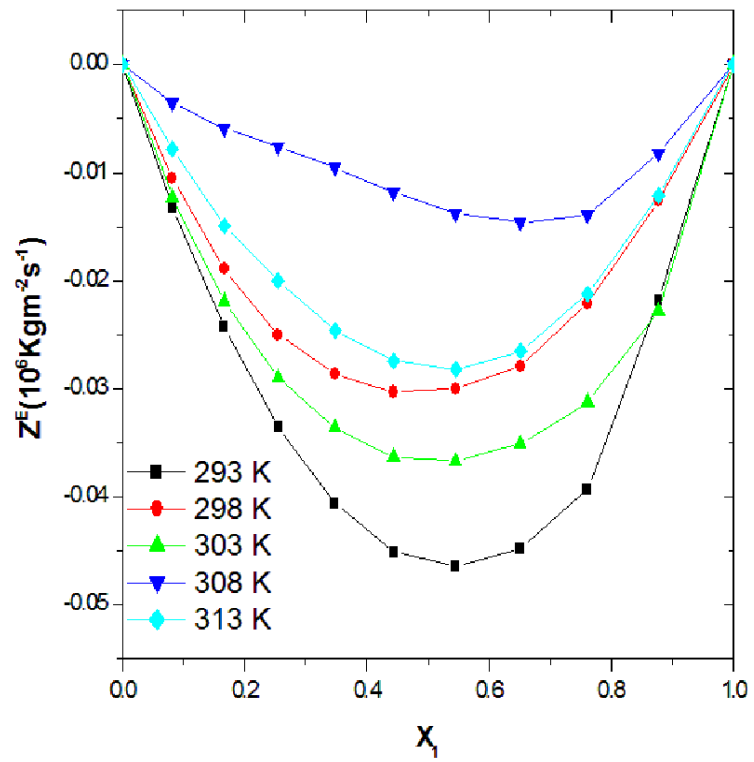

Fig. 7. Plots of $Z^{\mathrm{E}}$ Vs. $X_{1}$ for $\mathrm{DOX}+\mathrm{TOL}$

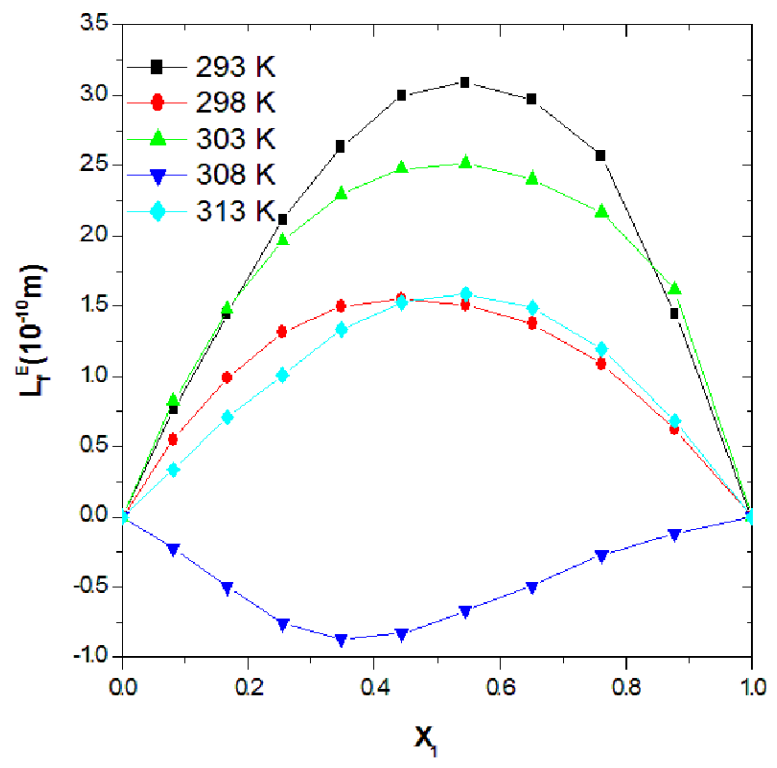

Fig. 6. Plots of $\mathrm{L}_{\mathrm{f}}^{\mathrm{E}}$ Vs. $\mathrm{X}_{1}$ for $\mathrm{DOX}+\mathrm{TOL}$

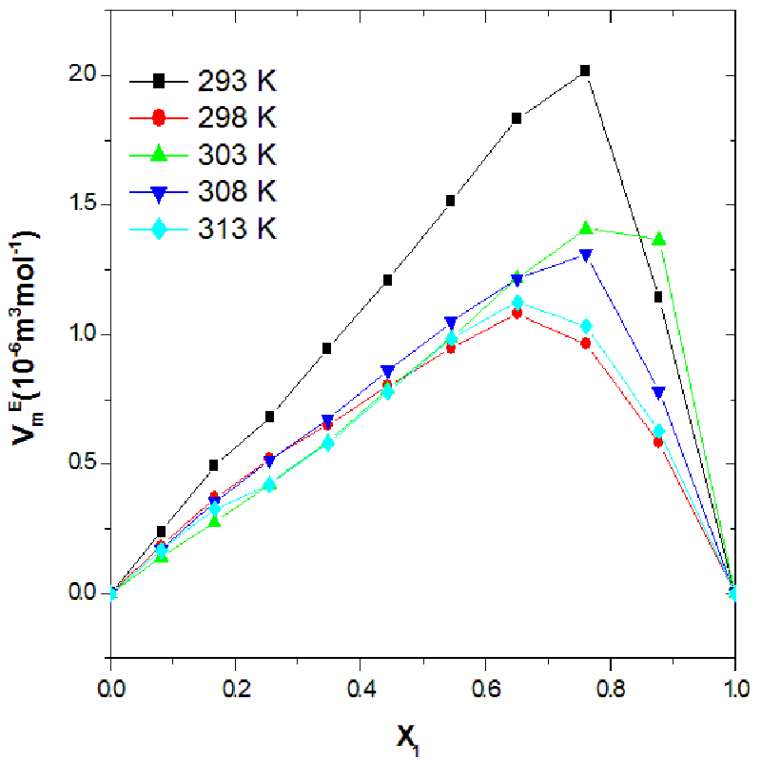

Fig. 8. Plots of $V_{m}{ }^{E} V s . X_{1}$ for $D O X+T O L$ 


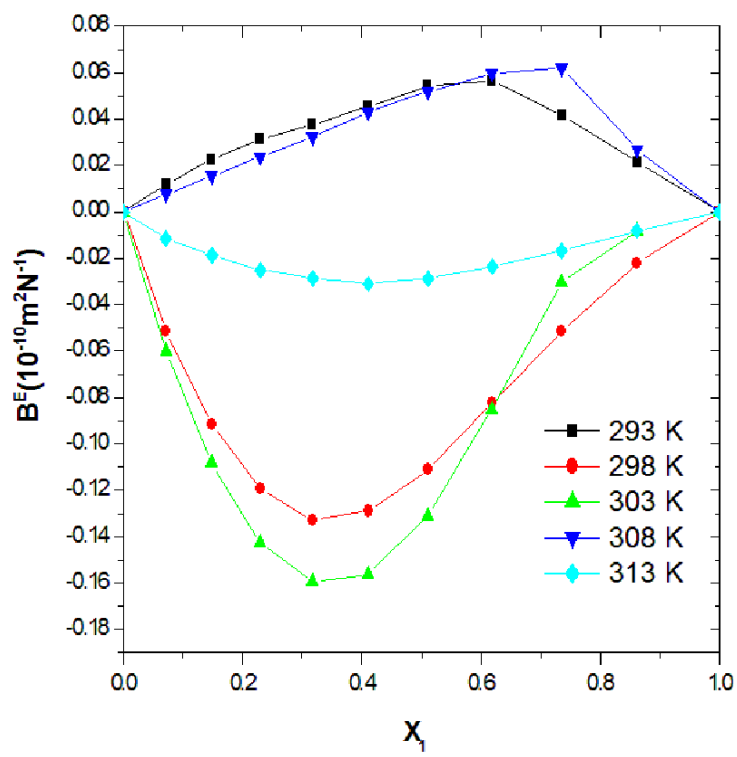

Fig. 9. Plots of $\beta^{\mathrm{E}}$ Vs. $\mathrm{X}_{1}$ for $\mathrm{DOX}+\mathrm{ETB}$

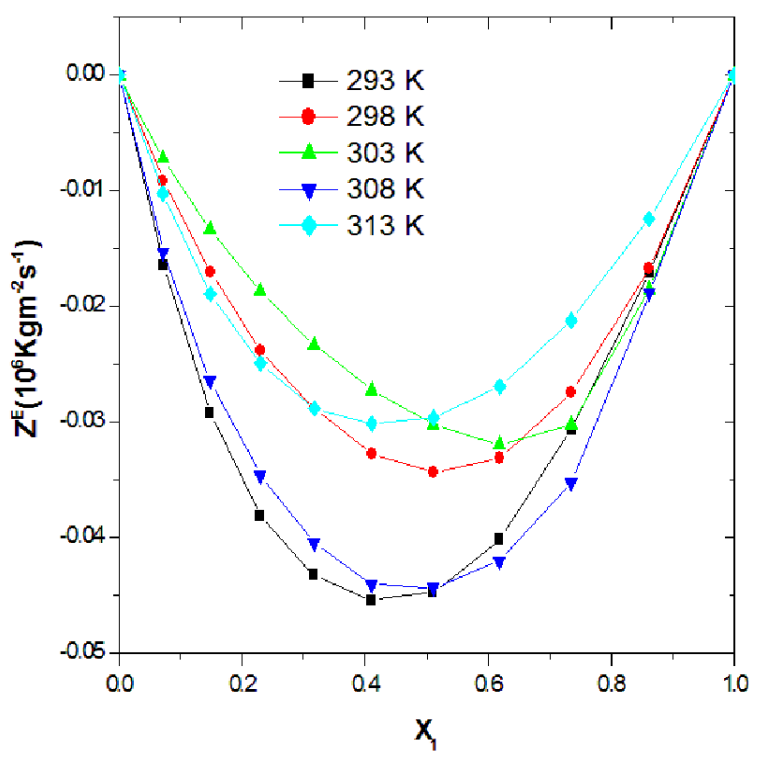

Fig. 11. Plots of $Z^{\mathrm{E}}$ Vs. $X_{1}$ for $D O X+E T B$

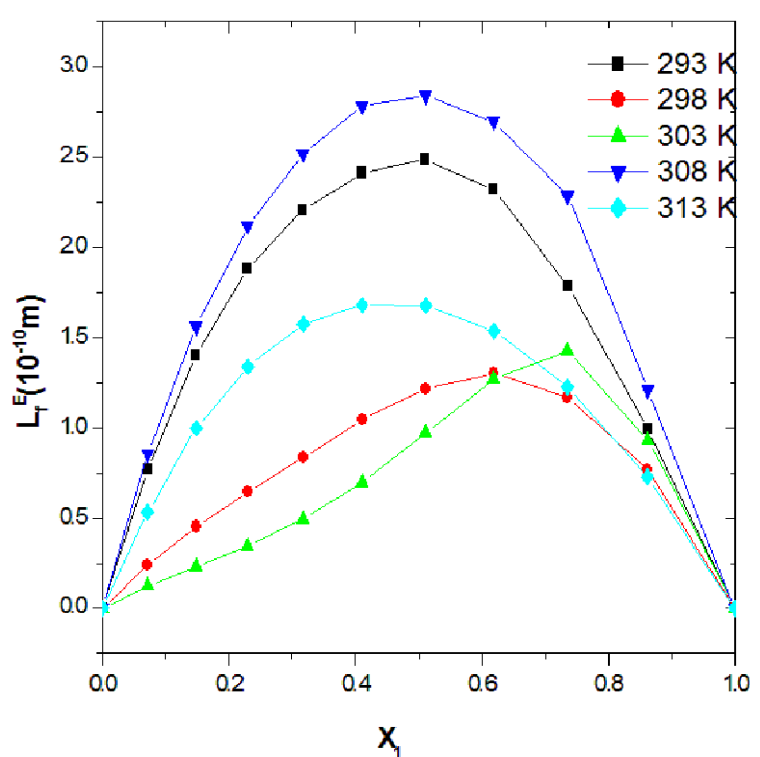

Fig. 10. Plots of $L_{f}^{E}$ Vs. $X_{1}$ for DOX+ETB

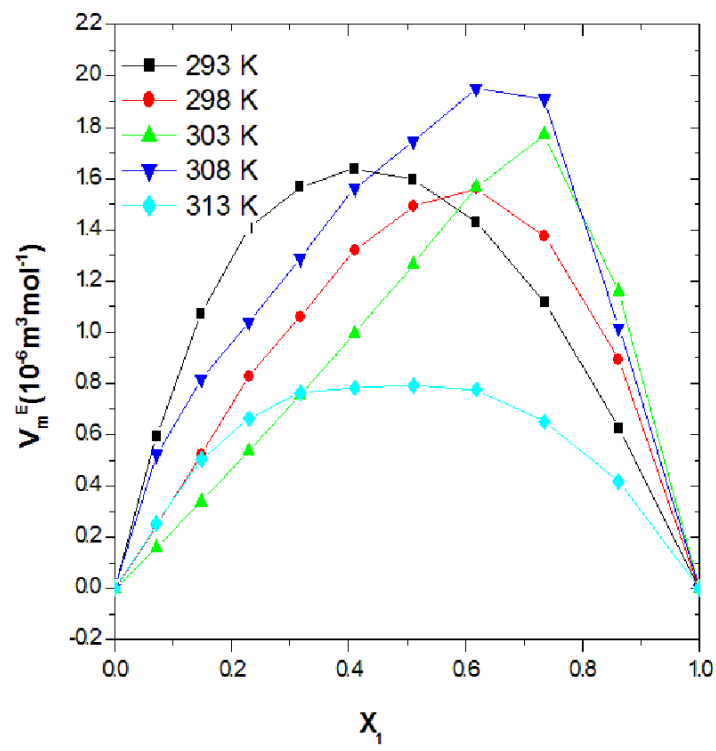

Fig. 12. Plots of $V_{m}{ }^{E} V s . X_{1}$ for DOX $+E T B$ 
Table 1. Values of $A_{i}$ parameters, $\sigma\left(Y^{E}\right)$ for the binary liquid mixtures at $293 \mathrm{~K}$.

\begin{tabular}{|c|c|c|c|c|c|c|c|}
\hline Property & $\mathbf{T} / \mathbf{K}$ & $\mathbf{A}_{0}$ & $\mathbf{A}_{1}$ & $\mathbf{A}_{2}$ & $\mathbf{A}_{3}$ & $\mathbf{A}_{4}$ & $\sigma\left(\mathbf{Y}^{\mathbf{E}}\right)$ \\
\hline \multicolumn{8}{|c|}{$\mathrm{DOX}+\mathrm{ANS}$} \\
\hline $10^{10} \mathrm{Lf}^{\mathrm{E}} /(\mathrm{m})$ & $293 \mathrm{~K}$ & -4.0446 & -0.3117 & 0.8337 & -1.5791 & -0.7983 & 0.01156 \\
\hline $10^{6} \mathrm{Vm}^{\mathrm{E}} /\left(\mathrm{m}^{3} \mathrm{~mol}^{-1}\right)$ & & -1.0991 & 0.1716 & 0.1259 & -0.2845 & -0.8465 & 0.003582 \\
\hline $10^{-6} \mathrm{Z}^{\mathrm{E}} /\left(\mathrm{Kgm}^{-2} \mathrm{~S}^{-1}\right)$ & & 0.0414 & 0.0016 & -0.0104 & 0.0178 & 0.0146 & 0.000123 \\
\hline $10^{10} \beta^{\mathrm{E}} /\left(\mathrm{m}^{2} \mathrm{~N}^{-1}\right)$ & & -0.3255 & -0.0259 & 0.0602 & -0.1152 & -0.0622 & 0.000845 \\
\hline \multicolumn{8}{|c|}{$\mathrm{DOX}+\mathrm{TOL}$} \\
\hline $10^{10} \mathrm{Lf}^{\mathrm{E}} /(\mathrm{m})$ & $293 \mathrm{~K}$ & 12.3343 & -2.8909 & 1.6471 & 0.9816 & -3.7757 & 0.070299 \\
\hline $10^{6} \mathrm{Vm}^{\mathrm{E}} /\left(\mathrm{m}^{3} \mathrm{~mol}^{-1}\right)$ & & 5.4408 & -7.6544 & 9.5229 & 4.4319 & -11.257 & 0.104099 \\
\hline $10^{-6} \mathrm{Z}^{\mathrm{E}} /\left(\mathrm{Kgm}^{-2} \mathrm{~S}^{-1}\right)$ & & -0.1842 & 0.0405 & -0.0614 & -0.0328 & 0.0859 & 0.001061 \\
\hline $10^{10} \beta^{\mathrm{E}} /\left(\mathrm{m}^{2} \mathrm{~N}^{-1}\right)$ & & 0.4068 & -0.3797 & 0.1239 & 0.0856 & -0.3135 & 0.005761 \\
\hline \multicolumn{8}{|c|}{$\mathrm{DOX}+\mathrm{ETB}$} \\
\hline $10^{10} \mathrm{Lf}^{\mathrm{E}} /(\mathrm{m})$ & $293 \mathrm{~K}$ & 9.9767 & 0.5546 & -0.3668 & 2.6673 & -0.1568 & 0.031213 \\
\hline $10^{6} \mathrm{Vm}^{\mathrm{E}} /\left(\mathrm{m}^{3} \mathrm{~mol}^{-1}\right)$ & & 6.4061 & 1.7735 & 1.6111 & 0.932 & -1.2501 & 0.013469 \\
\hline $10^{-6} \mathrm{Z}^{\mathrm{E}} /\left(\mathrm{Kgm}^{-2} \mathrm{~S}^{-1}\right)$ & & -0.1793 & -0.0452 & -0.0202 & -0.0323 & 0.0086 & 0.000324 \\
\hline $10^{10} \beta^{\mathrm{E}} /\left(\mathrm{m}^{2} \mathrm{~N}^{-1}\right)$ & & 0.2132 & -0.1051 & -0.0624 & 0.2057 & -0.021 & 0.002502 \\
\hline
\end{tabular}

Table 2. Values of $A_{i}$ parameters, $\sigma\left(Y^{E}\right)$ for the binary liquid mixtures at $298 \mathrm{~K}$.

\begin{tabular}{|c|c|c|c|c|c|c|c|}
\hline Property & $\mathbf{T} / \mathbf{K}$ & $\mathbf{A}_{0}$ & $\mathbf{A}_{1}$ & $\mathbf{A}_{2}$ & $\mathbf{A}_{3}$ & $\mathbf{A}_{4}$ & $\sigma\left(\mathbf{Y}^{\mathrm{E}}\right)$ \\
\hline \multicolumn{8}{|c|}{ DOX+ANS } \\
\hline $10^{10} \mathrm{Lf}^{\mathrm{E}} /(\mathrm{m})$ & $298 \mathrm{~K}$ & -3.403 & -0.1875 & 3.2031 & -0.7722 & -2.2501 & 0.032228 \\
\hline $10^{6} \mathrm{Vm}^{\mathrm{E}} /\left(\mathrm{m}^{3} \mathrm{~mol}^{-1}\right)$ & & -1.2115 & 0.2647 & 0.7025 & -0.7035 & -1.3458 & 0.009458 \\
\hline $10^{-6} \mathrm{Z}^{\mathrm{E}} /\left(\mathrm{Kgm}^{-2} \mathrm{~S}^{-1}\right)$ & & 0.0345 & -0.0007 & -0.0348 & 0.0137 & 0.0287 & 0.00036 \\
\hline $10^{10} \beta^{\mathrm{E}} /\left(\mathrm{m}^{2} \mathrm{~N}^{-1}\right)$ & & -0.2666 & -0.0168 & 0.2352 & -0.0556 & -0.1672 & 0.00236 \\
\hline \multicolumn{8}{|c|}{$\mathrm{DOX}+\mathrm{TOL}$} \\
\hline $10^{10} \mathrm{Lf}^{\mathrm{E}} /(\mathrm{m})$ & $298 \mathrm{~K}$ & 6.1713 & 0.8952 & 1.6204 & 0.0792 & -1.7333 & 0.0092 \\
\hline $10^{6} \mathrm{Vm}^{\mathrm{E}} /\left(\mathrm{m}^{3} \mathrm{~mol}^{-1}\right)$ & & 3.5582 & -3.196 & 2.7443 & 2.3413 & -3.4826 & 0.016782 \\
\hline $10^{-6} \mathrm{Z}^{\mathrm{E}} /\left(\mathrm{Kgm}^{-2} \mathrm{~S}^{-1}\right)$ & & -0.1217 & -0.0052 & -0.0297 & -0.0156 & 0.0327 & 0.000162 \\
\hline $10^{10} \beta^{\mathrm{E}} /\left(\mathrm{m}^{2} \mathrm{~N}^{-1}\right)$ & & -0.1478 & -0.059 & 0.1079 & -0.0012 & -0.1452 & 0.000756 \\
\hline \multicolumn{8}{|c|}{$\mathrm{DOX}+\mathrm{ETB}$} \\
\hline $10^{10} \mathrm{Lf}^{\mathrm{E}} /(\mathrm{m})$ & $298 \mathrm{~K}$ & 4.8118 & -2.8594 & 0.2441 & 1.6827 & 0.2226 & 0.009115 \\
\hline $10^{6} \mathrm{Vm}^{\mathrm{E}} /\left(\mathrm{m}^{3} \mathrm{~mol}^{-1}\right)$ & & 5.9186 & -2.7153 & 0.2032 & 0.7615 & -0.8256 & 0.020733 \\
\hline $10^{-6} \mathrm{Z}^{\mathrm{E}} /\left(\mathrm{Kgm}^{-2} \mathrm{~S}^{-1}\right)$ & & -0.1371 & 0.0122 & -0.0023 & -0.0161 & 0.0022 & 0.000197 \\
\hline $10^{10} \beta^{\mathrm{E}} /\left(\mathrm{m}^{2} \mathrm{~N}^{-1}\right)$ & & -0.454 & -0.4398 & -0.013 & 0.1214 & 0.0037 & 0.00074 \\
\hline
\end{tabular}


Table 3. Values of $A_{i}$ parameters, $\sigma\left(Y^{E}\right)$ for the binary liquid mixtures at $303 \mathrm{~K}$.

\begin{tabular}{|c|c|c|c|c|c|c|c|}
\hline Property & $T / K$ & $\mathbf{A}_{0}$ & $\mathbf{A}_{1}$ & $\mathbf{A}_{2}$ & $\mathbf{A}_{3}$ & $\mathbf{A}_{4}$ & $\sigma\left(\mathbf{Y}^{\mathbf{E}}\right)$ \\
\hline \multicolumn{8}{|c|}{ DOX+ANS } \\
\hline $10^{10} \mathrm{Lf}^{\mathrm{E}} /(\mathrm{m})$ & $303 \mathrm{~K}$ & -2.9132 & -1.4287 & 3.0126 & 0.8669 & -2.8226 & 0.021101 \\
\hline $10^{6} \mathrm{Vm}^{\mathrm{E}} /\left(\mathrm{m}^{3} \mathrm{~mol}^{-1}\right)$ & & -0.9923 & -0.3471 & 0.4338 & 0.1486 & -0.5052 & 0.006209 \\
\hline $10^{-6} \mathrm{Z}^{\mathrm{E}} /\left(\mathrm{Kgm}^{-2} \mathrm{~S}^{-1}\right)$ & & 0.027 & 0.0153 & -0.03 & -0.0096 & 0.0284 & 0.000234 \\
\hline $10^{10} \beta^{\mathrm{E}} /\left(\mathrm{m}^{2} \mathrm{~N}^{-1}\right)$ & & -0.2268 & -0.1087 & 0.2204 & 0.0655 & -0.2073 & 0.001565 \\
\hline \multicolumn{8}{|c|}{$\mathrm{DOX}+\mathrm{TOL}$} \\
\hline $10^{10} \mathrm{Lf}^{\mathrm{E}} /(\mathrm{m})$ & $303 \mathrm{~K}$ & 10.0567 & -0.3482 & 3.0991 & -4.3337 & 3.4575 & 0.011538 \\
\hline $10^{6} \mathrm{Vm}^{\mathrm{E}} /\left(\mathrm{m}^{3} \mathrm{~mol}^{-1}\right)$ & & 3.5882 & -3.9088 & 3.756 & -5.6241 & 4.8109 & 0.016456 \\
\hline $10^{-6} \mathrm{Z}^{\mathrm{E}} /\left(\mathrm{Kgm}^{-2} \mathrm{~S}^{-1}\right)$ & & -0.147 & 0.0048 & -0.0449 & 0.0513 & -0.0428 & 0.00013 \\
\hline $10^{10} \beta^{\mathrm{E}} /\left(\mathrm{m}^{2} \mathrm{~N}^{-1}\right)$ & & 0.1348 & -0.1838 & 0.23 & -0.3817 & 0.2969 & 0.000986 \\
\hline \multicolumn{8}{|c|}{ DOX+ETB } \\
\hline $10^{10} \mathrm{Lf}^{\mathrm{E}} /(\mathrm{m})$ & $303 \mathrm{~K}$ & 3.7688 & -6.3436 & 5.2133 & 4.1031 & -5.7457 & 0.033074 \\
\hline $10^{6} \mathrm{Vm}^{\mathrm{E}} /\left(\mathrm{m}^{3} \mathrm{~mol}^{-1}\right)$ & & 4.9501 & -6.6223 & 6.6876 & 3.1337 & -7.6887 & 0.058144 \\
\hline $10^{-6} \mathrm{Z}^{\mathrm{E}} /\left(\mathrm{Kgm}^{-2} \mathrm{~S}^{-1}\right)$ & & -0.1198 & 0.0602 & -0.0614 & -0.048 & 0.0734 & 0.000483 \\
\hline $10^{10} \beta^{\mathrm{E}} /\left(\mathrm{m}^{2} \mathrm{~N}^{-1}\right)$ & & -0.5387 & -0.7157 & 0.4082 & 0.3164 & -0.4901 & 0.002814 \\
\hline
\end{tabular}

Table 4. Values of $A_{i}$ parameters, $\sigma\left(\mathrm{Y}^{\mathrm{E}}\right)$ for the binary liquid mixtures at $308 \mathrm{~K}$.

\begin{tabular}{|c|c|c|c|c|c|c|c|}
\hline Property & $\mathbf{T} / \mathbf{K}$ & $\mathbf{A}_{0}$ & $\mathbf{A}_{1}$ & $\mathbf{A}_{2}$ & $\mathbf{A}_{3}$ & $\mathbf{A}_{4}$ & $\sigma\left(\mathbf{Y}^{\mathbf{E}}\right)$ \\
\hline \multicolumn{8}{|c|}{ DOX+ANS } \\
\hline $10^{10} \mathrm{Lf}^{\mathrm{E}} /(\mathrm{m})$ & $308 \mathrm{~K}$ & -8.4309 & -5.3322 & 6.5492 & 3.7703 & -5.3075 & 0.04249 \\
\hline $10^{6} \mathrm{Vm}^{\mathrm{E}} /\left(\mathrm{m}^{3} \mathrm{~mol}^{-1}\right)$ & & -2.1631 & -1.2445 & 3.2189 & 1.1491 & -2.6876 & 0.007855 \\
\hline $10^{-6} \mathrm{Z}^{\mathrm{E}} /\left(\mathrm{Kgm}^{-2} \mathrm{~S}^{-1}\right)$ & & 0.0829 & 0.0559 & -0.0803 & -0.043 & 0.0642 & 0.000424 \\
\hline $10^{10} \beta^{\mathrm{E}} /\left(\mathrm{m}^{2} \mathrm{~N}^{-1}\right)$ & & -0.6355 & -0.4043 & 0.4768 & 0.2781 & -0.3888 & 0.00317 \\
\hline \multicolumn{8}{|c|}{$\mathrm{DOX}+\mathrm{TOL}$} \\
\hline $10^{10} \mathrm{Lf}^{\mathrm{E}} /(\mathrm{m})$ & $308 \mathrm{~K}$ & -3.0318 & -3.072 & 0.7461 & 2.8238 & 1.164 & 0.017542 \\
\hline $10^{6} \mathrm{Vm}^{\mathrm{E}} /\left(\mathrm{m}^{3} \mathrm{~mol}^{-1}\right)$ & & 3.803 & -4.5193 & 5.4934 & 1.9918 & -6.1158 & 0.056604 \\
\hline $10^{-6} \mathrm{Z}^{\mathrm{E}} /\left(\mathrm{Kgm}^{-2} \mathrm{~S}^{-1}\right)$ & & -0.0514 & 0.0424 & -0.0288 & -0.0352 & 0.0213 & 0.00036 \\
\hline $10^{10} \beta^{\mathrm{E}} /\left(\mathrm{m}^{2} \mathrm{~N}^{-1}\right)$ & & -0.9465 & -0.3392 & 0.0585 & 0.216 & 0.0764 & 0.001412 \\
\hline \multicolumn{8}{|c|}{$\mathrm{DOX}+\mathrm{ETB}$} \\
\hline $10^{10} \mathrm{Lf}^{\mathrm{E}} /(\mathrm{m})$ & $308 \mathrm{~K}$ & 11.3788 & -0.5375 & 2.7251 & 3.8577 & -5.1476 & 0.042438 \\
\hline $10^{6} \mathrm{Vm}^{\mathrm{E}} /\left(\mathrm{m}^{3} \mathrm{~mol}^{-1}\right)$ & & 7.0108 & -5.5109 & 4.6205 & 7.7552 & -6.1236 & 0.079504 \\
\hline $10^{-6} \mathrm{Z}^{\mathrm{E}} /\left(\mathrm{Kgm}^{-2} \mathrm{~S}^{-1}\right)$ & & -17.8248 & 0.0011 & -0.0437 & -0.0706 & 0.054 & 6.728339 \\
\hline $10^{10} \beta^{\mathrm{E}} /\left(\mathrm{m}^{2} \mathrm{~N}^{-1}\right)$ & & 0.2037 & -0.2391 & 0.1863 & 0.3113 & -0.4403 & 0.00357 \\
\hline
\end{tabular}


Table 5. Values of $A_{i}$ parameters, $\sigma\left(\mathrm{Y}^{\mathrm{E}}\right)$ for the binary liquid mixtures at $313 \mathrm{~K}$.

\begin{tabular}{|c|c|c|c|c|c|c|c|}
\hline Property & $\mathbf{T} / \mathbf{K}$ & $\mathbf{A}_{0}$ & $\mathbf{A}_{1}$ & $\mathbf{A}_{2}$ & $\mathbf{A}_{3}$ & $\mathbf{A}_{4}$ & $\sigma\left(\mathbf{Y}^{\mathrm{E}}\right)$ \\
\hline \multicolumn{8}{|c|}{ DOX+ANS } \\
\hline $10^{10} \mathrm{Lf}^{\mathrm{E}} /(\mathrm{m})$ & $313 \mathrm{~K}$ & -8.6517 & -9.9996 & -1.5166 & 3.4465 & -4.6937 & 0.12044 \\
\hline $10^{6} \mathrm{Vm}^{\mathrm{E}} /\left(\mathrm{m}^{3} \mathrm{~mol}^{-1}\right)$ & & -1.1224 & -0.778 & -0.1404 & 0.7483 & 0.5263 & 0.010344 \\
\hline $10^{-6} \mathrm{Z}^{\mathrm{E}} /\left(\mathrm{Kgm}^{-2} \mathrm{~S}^{-1}\right)$ & & 0.074 & 0.0892 & 0.013 & -0.037 & 0.0343 & 0.001082 \\
\hline $10^{10} \beta^{\mathrm{E}} /\left(\mathrm{m}^{2} \mathrm{~N}^{-1}\right)$ & & -0.6385 & -0.757 & -0.1215 & 0.2441 & -0.3633 & 0.010825 \\
\hline \multicolumn{8}{|c|}{$\mathrm{DOX}+\mathrm{TOL}$} \\
\hline $10^{10} \mathrm{Lf}^{\mathrm{E}} /(\mathrm{m})$ & $313 \mathrm{~K}$ & 6.3191 & -1.2228 & -1.4204 & 0.2472 & 0.2358 & 0.020574 \\
\hline $10^{6} \mathrm{Vm}^{\mathrm{E}} /\left(\mathrm{m}^{3} \mathrm{~mol}^{-1}\right)$ & & 3.5789 & -4.2151 & 2.0514 & 3.2656 & -2.1042 & 0.016069 \\
\hline $10^{-6} \mathrm{Z}^{\mathrm{E}} /\left(\mathrm{Kgm}^{-2} \mathrm{~S}^{-1}\right)$ & & -0.1125 & 0.0154 & 0.0014 & -0.0186 & 0.0078 & 0.000249 \\
\hline $10^{10} \beta^{\mathrm{E}} /\left(\mathrm{m}^{2} \mathrm{~N}^{-1}\right)$ & & -0.1854 & -0.2373 & -0.1323 & 0.0252 & 0.0196 & 0.001649 \\
\hline \multicolumn{8}{|c|}{$\mathrm{DOX}+\mathrm{ETB}$} \\
\hline $10^{10} \mathrm{Lf}^{\mathrm{E}} /(\mathrm{m})$ & $313 \mathrm{~K}$ & 6.7281 & 1.1717 & 0.9132 & 0.0805 & -0.6979 & 0.009457 \\
\hline $10^{6} \mathrm{Vm}^{\mathrm{E}} /\left(\mathrm{m}^{3} \mathrm{~mol}^{-1}\right)$ & & 3.1745 & 0.2121 & 2.0929 & 0.1969 & -2.0284 & 0.016492 \\
\hline $10^{-6} \mathrm{Z}^{\mathrm{E}} /\left(\mathrm{Kgm}^{-2} \mathrm{~S}^{-1}\right)$ & & -0.119 & -0.0283 & -0.0259 & -0.0058 & 0.0208 & 0.000177 \\
\hline $10^{10} \beta^{\mathrm{E}} /\left(\mathrm{m}^{2} \mathrm{~N}^{-1}\right)$ & & -0.1169 & -0.0564 & 0.041 & -0.0018 & -0.0582 & 0.000759 \\
\hline
\end{tabular}

\section{CONCLUSION}

Positive deviations of excess values of $\mathrm{Lf}^{\mathrm{E}}, \mathrm{V}_{\mathrm{m}}{ }^{\mathrm{E}}, \mathrm{Z}^{\mathrm{E}}$ and $\beta^{\mathrm{E}}$ in binary systems have been attributed to dispersive forces and negative deviation is due to dipole-dipole and induced dipole interactions. From excess values it has been concluded that the binary liquid mixtures of DOX which is polar and aliphatic solvent with aromatic solvents like ANS, TOL and ETB shows strong molecular interactions. The intermolecular interaction of DOX with ANS is greater than ETB and TOL. It may be attributed due to strong dipole-dipole interactions between the molecules of DOX and ANS.

\section{Acknowledgement}

The authors wish to express their sincere gratitude to the Principal Hislop College, Nagpur for providing necessary facilities.

\section{References}

[1] Kumar H., Dipika, Int. J. Chem. Sci. Tech. 2 (2012) 1.

[2] Singh J., Mohanty G. C., Acharya S., Int. J. Sci. Res. Publ. 2 (2012) 22.

[3] Pund D. A., Int. J. Chem. Phy. Sci. 2 (2013) 1.

[4] Dhondage S. S., Pandhurnekar C. P., S., Gharde K., J. Chem. Eng. Data 56 (2011) 3484 . 
[5] Ali A., Nain A. K., Sharma V. K., Ahmad S., Acoust. Lett. 24 (2000) 9.

[6] Rajaguru P., Jayaraj, Acoust. Lett. 13 (1990) 142.

[7] Redlitch O., Kister A. T., Indus. Eng. Chem. 40 (1998) 345.

[8] Nikam P. S., Jadhav M. C., Hasan M., Indian J. Pure Appl. Phys. 33 (1995) 398.

[9] Roy M. N., Sinha B., Dakua V. K., J. Mol. Liq. 136 (2007) 128.

[10] Ali A., Nabi F., J. Mol. Liq. 143 (2008) 141.

[11] Bhuiyan M. M., Uddin M. H., J. Mol. Liq. 138 (2008) 139.

[12] Mozo I., Gonzalez J. A., de la Fuente I. G., Cobos J. C., Riesco N., J. Mol. Liq. 140 (2008) 87.

[13] Rathnam M. V., Mohite S., Kumar M. S., J. Chem. Eng. Data 54 (2009) 305.

[14] Raj A. M., Reshmi L. B., Jothy V. B., Jayachandran M., Sanjeeviraja C., Fluid Phase Equilib. 281 (2009) 78.

[15] Saxena C. M., Saxena A., Srivastava A. K., Shukla N. K., J. Am. Chem. Sci. 3 (2013) 468.

[16] Azhagiri S., Jayakumar S., Padmanaban R., Gunasekaran S., Srinivasan S., J. Solution Chem., 38 (2009) 441.

[17] Treszczanowicz A. J., Kiyohara O., Benson G. C., J. Chem. Thermodyn. 13 (1981) 253.

[18] Gracia B., Alcalde R., Leal J. M., Matos J. S., J. Chem. Soc. Faraday Trans. 92 (1996) 3347.

[19] Raghuwanshi P. B., Mahalle P. V., Sci. Revs. Chem. Commun. 4 (2014) 30.

[20] Mehra R., Israni R., Indian J. Chem. Tech. 9 (2001) 341.

[21] Parmanik R., Bagehi S., J. Indian Chem. Soc. 80 (2003) 335.

[22] Arul G., Palaniappan L., Indian J. Pure Appl. Phys. 43 (2005) 755.

[23] Rena A., Clara C., Ana, Gomaz marigliona., Horacio, N. Solimo., J. Chem. Eng. Data $51(2006) 1473$.

[24] Becu L., Manneville S., Colin A., Phys. Rev. Lett. 76 (2006) 13. 